\title{
INTERVIEW MED PROFESSOR CLIFFORD GEERTZ
}

\author{
Arun Micheelsen
}

\section{Indledning}

Den 18. oktober 2000 havde jeg æren af at interviewe professor Clifford Geertz ved Institute for Advanced Studies, Princeton, USA. ${ }^{1}$ Fra sin entre på den akademiske scene med afhandlingen om religion i Indonesien (Geertz 1960) har han med sin vægtning af den fortolkende tilgang til kulturen været en bærende kraft i udviklingen inden for den moderne antropologi - en tilgang, som han senere døbte den fortolkende antropologi eller kulturantropologi (Geertz 1983, 7; 1995, 114). Videre har han, med sin berømte definition af religion som et kulturelt system, bekræftet sin position som en uomgængelig del af den religionsvidenskabelige fagtradition. Ideen om religion som et kulturelt system, som for Geertz også betyder, at det er et symbolsystem, har netop åbnet muligheden for en undersøgelse af de mekanismer og immanente processer, der skaber og varetager betydning inden for en kulturel og historisk ramme. Desværre er Geertz’ projekt ikke så ligetil. Med sin litterære stil, sin forkærlighed for essayet og den slet skjulte humor, som han benytter sig af i sin forskning, kan det være problematisk at placere den fortolkende antropologis videnskabelighed i forlængelse af den humanistiske og samfundsvidenskabelige videnskab. Dette skyldes Geertz' egen teoretisering, metodik og almene refleksioner over det antropologiske foretagende, som på den ene side må siges at ligge i forlængelse af den humanistiske og socialvidenskabelige fagtradition, og på den anden side netop har muliggjort en innovation af den antropologiske forskning og en revurdering af antropologiens fagdisciplinære baggrund (Geertz 1993, 87-89). Derfor var det min hensigt med et interview at få konkrete og uddybende svar på Geertz' faghistoriske baggrund, hans bagvedliggende teori om betydning, hans opfattelse af og mening om metode og endelig en afklaring af hans symboldefinition.

Da det er mit ønske, at interviewet i så høj grad som muligt skal repræsentere Geertz' egne holdninger og meninger, som de fremstod under interviewet, har jeg forsøgt at fastholde hans egne formuleringer i teksten. Konsekvensen af dette er, at interviewet uomgængeligt vil indeholde uklarheder og manglende forklaringer, som jeg har valgt ikke at uddybe, da en sådan uddybelse i sidste instans blot vil være min fortolkning af Clifford Geertz.

\footnotetext{
${ }^{1}$ Dette interview er blevet til på eget initiativ. Dog vil jeg gerne takke Jeppe Sinding Jensen og specielt Armin W. Geertz for deres hjælp og vejledning ved forberedelsen af interviewet. Videre ønsker jeg også at takke Det Teologiske Fakultet ved Aarhus Universitet for økonomisk støtte til rejsen.
} 


\section{Interview}

AM: Jeg vil gerne begynde med at spørge dig, hvorledes du kom til at fokusere så eksplicit på fænomenet kultur?

CG: I Available Light giver jeg en længere forklaring på, hvordan jeg - som assistent - arbejdede sammen med Kluckhohn og Kroeber i forbindelse med deres bog om kultur (1963, v), hvilket selvfølgelig har påvirket mig (Geertz 2000, 12f; Handler 1991, 604). Den anden grund er, at jeg har en humanistisk baggrund. Jeg havde før Harvard studeret filosofi og litteratur - ikke antropologi. Jeg havde faktisk aldrig haft et kursus i antropologi, før jeg kom til Harvard. Derfor var det naturligt, at jeg med den baggrund fokuserede på kultur.

AM: Var dit feltarbejde i Indonesien (i 1950'erne) også med til at skærpe din interesse for kultur?

CG: Da jeg rejste til Indonesien, som en del af et hold på ni personer, var det min opgave at studere religion, hvilket hurtigt involverer én i kulturelle forhold. Fordi jeg skrev min afhandling om religion (Geertz 1960), endte jeg ved kultur, men jeg ville være endt med det emne før eller siden.

AM: I Person, Time, and Conduct in Bali skriver du:

What we want and do not yet have is a developed method of describing and analyzing the meaningful structure of experience (here, the experience of persons) as it is apprehended by representative members of a particular society at a particular point in time - in a word, a scientific phenomenology of culture (Geertz 1966, 7).

Føler du, at du er nået frem til en videnskabelig kulturfænomenologi?

CG: Jeg ved ikke, om jeg har nået den, men jeg fortsætter dog med at arbejde hen imod den. Jeg har lige afholdt et seminar sammen med Thomas Luckmann. Vi talte en del om fænomenologi - hans tilgang og min. Min fænomenologiske tilgang er ikke ulig Luckmanns eller Peter Bergers (Berger \& Luckmann 1967). Dog er fænomenologien for dem - som for Edmund Husserl - et emne, der går forud for alt andet. De forholder sig til fænomenologien før analysen, forstået som en generel overvejelse over menneskets livsverden. Jeg har ikke noget imod dette, men det er ikke den måde, jeg arbejder på. Jeg arbejder direkte empirisk. Derfor sker enhver form for fænomenologisk udvikling i mine tanker i sammenhæng med analysen af materialet. For mig er fænomenologien ikke en bagvedliggende idé om kulturen. Det vil sige, at jeg ikke har en prækonstituerende filosofi om kulturen. Jeg er som sagt ikke imod deres tilgang, men det er ikke det, jeg beskæftiger mig med. Spørgsmålet om videnskab er en anden sag her. Dog synes jeg, at jeg har udøvet en kulturfænomenologi i hele mit arbejde. Ikke kun i Person, Time, and Conduct in Bali, men også i Negara hvor jeg fænomenologisk skriver om magt (Geertz 1980, 85). Måske brugte jeg ikke de termer dengang - men i den generelle tilgang jeg har, hvor jeg lægger vægt på at beskrive den livsverden, mennesket lever i, bruger jeg i højere grad Wittgenstein end Husserl. Det jeg skrev om videnskab i 
Person, Time, and Conduct in Bali, ville jeg nok ikke have skrevet nu. Jeg synes nu heller ikke, at jeg har nået et omegapunkt, dvs. en afsluttet videnskabelig fænomenologi om kulturen. Jeg har som sagt prøvet at udvikle en generel fænomenologisk tilgang til kulturen, hvis ikke andet, så en tilgang i overensstemmelse med Luckmanns og Bergers fænomenologi. Der er selvfølgelig problemer med Husserl såsom det transcendentale ego og den cartesianske tilbøjelighed, der eksisterer i visse former for fænomenologi, men jeg har lært meget af disse tænkere og prøvet på at bruge dem i mit arbejde. Specielt som tiden går, hvor min interesse for, hvorledes mennesker opfatter deres generelle verden og deres specifikke livsverden, vokser.

AM: Betyder det også, at du benytter dig af en hermeneutisk tilgang?

CG: Ja - jeg er meget influeret af Paul Ricoeur og Hans-Georg Gadamer. ${ }^{2}$ Nok mest af Ricoeur. Men hermeneutikken fører uundgåeligt én ind i fænomenologien, hvis ikke andet, så ind i en fænomenologisk-deskriptiv tilgang (Geertz 1980, 103f). Igen - jeg arbejder empirisk. Både Ricoeur og Gadamer er interesseret i den generelle mulighed for viden, som jeg selvfølgelig har lært meget af, men det er ikke det, jeg gør. Jeg prøver at få en viden om noget. Jeg prøver at udøve en anvendt fænomenologi, en anvendt hermeneutik. Det vil sige at udføre et hermeneutisk arbejde med, hvad det end er, man ønsker at forstå; eksempelvis en hanekamp, som er et eksempel på ét forsøg, hvor jeg bevæger mig fra en fænomenologisk til en hermeneutisk tilgang og tilbage igen - hvilket også er synligt i From the Native's Point of View (1980, 103f; 1983, 55; 1995, 114). Så jeg ser mig selv som tilhørende den fænomenologiske tradition, selvom jeg er lidt tilbageholdende over for en generel filosofi om kulturen.

AM: Kunne man i forlængelse af dette hævde, at du er eklektisk i dine teoretiske forudsætninger - for eksempel i din brug af Ludwig Wittgenstein, Susanne Langer, Gilbert Ryle, Talcott Parsons, Paul Ricoeur, Alfred Schutz, Max Weber og andre?

CG: Det er eklektisk forstået, således at de er forskellige tænkere, men de har alle det samme interesseområde, dvs. symbolet, betydning eller filosofien om sindet/ bevidstheden. ${ }^{3}$ Det var Parsons, der introducerede mig til Webers arbejde, så jeg har til en vis grad et parsonsk syn på Weber. Fortolkningen af Weber, og derfor også diskussionen angående Weber, handler om, hvorvidt han selv troede på en socialvidenskab med en videnskabelig tilgang til kulturen, eller om han troede på en fortolkende tilgang. Det er min opfattelse, at man kan læse ham på begge måder, selvom jeg bruger ham fra det

\footnotetext{
${ }^{2}$ Geertz har en del uspecifikke henvisninger til Paul Ricoeur. Dog henviser han til Ricoeur 1970. Det samme gælder for Hans-Georg Gadamer, men her er det ikke muligt at finde præcise henvisninger, hvilket er et typisk - og til tider frustrerende - træk ved Geertz’ forfatterskab.

${ }^{3}$ Da 'meaning' kan oversættes som både betydning og mening, og da disse to begreber har afvigende definition, er det afgørende, at der skelnes mellem dem. Generelt forstås 'mening' som det potentielle semantiske rum, der eksisterer inden for en given kultur og 'betydning' forstås som den aktualiserede semantik, eksempelvis via et tegn eller en diskurs. Som det forhåbentligt fremgår af dette interview, taler Geertz i højere grad om betydning end om mening. Videre tales der i forbindelse med Gilbert Ryle om 'mind', der desværre ikke lader sig oversætte direkte til dansk. Jeg har derfor valgt at oversætte mind til sind/bevidsthed vel vidende, at det ikke er en dækkende oversættelse.
} 
fortolkende perspektiv. Jeg er mere interesseret i religionssociologi end i typer af religiøsitet og almene klassificeringer af samme. Langer, Wittgenstein, Schutz og Ricoeur er alle interesserede i ‘betydning' i en eller anden form, og Ryle var interesseret i filosofien om sindet/bevidstheden (Ryle 1976). Så jeg synes ikke listen af nævnte personer er så eklektisk. Der er en del, som ikke er nævnt, eksempelvis er positivisterne ikke nævnt. Selvfølgelig kommer de fra forskellige discipliner, men listen har en indre sammenhæng.

AM: Følte du, da du begyndte at studere kultur, at der manglede redskaber inden for antropologien?

CG: Ja - jeg blev nødt til at orientere mig mod nye disciplinære græsgange. Først kiggede jeg på Langer og Ryle - men jeg har altid brugt Weber. Senere brugte jeg Wittgenstein, Gadamer og Schutz. Antropologien er en bedre bruger af begreber end en udvikler af dem. De fleste begreber er jo lånt fra andre discipliner, idet antropologien er så empirisk fokuseret, eller rettere var så empirisk fokuseret.

AM: I forbindelse med betydning skriver du:

... one cannot write a 'General Theory of Cultural Interpretation.' Or, rather, one can, but there appears to be little profit in it, because the essential task of theory building here is not to codify abstract regularities but to make thick description possible, not to generalize across cases but to generalize within them $(1993,26)$.

Er den partikulære fortolkning ikke baseret på en eller anden form for teori om betydning? Og hvis den er, hvad er så din teori om betydning?

CG: Nej - jeg tror ikke at en partikulær fortolkning skal være baseret på en generel teori om betydning, hvad det så end måtte være! Jeg er ikke en meningsrealist. Jeg tror ikke betydning er 'derude', så vi kan teoretisere om den. Man må prøve at se på folks adfærd, hvad de siger, og forsøge at få mening ud af det - det er min teoretiske tilgang til betydning. Men nej, jeg tror ikke, at jeg har brug for en generel teori om betydning. Det er også derfor, jeg sagde, at jeg afveg lidt fra fænomenologerne. De bekymrer sig om generelle forhold om mening, uafhængig af enhver form for empirisk case. Jeg bekymrer mig om, hvad noget betyder - hvad hanekampen betyder, hvad en begravelse betyder. Jeg har en konceptuel ramme - det skal man have - men en teori om betydning, som klassificerer betydning og formulerer love om mening/betydning, er ikke min stil. Jeg kan ikke huske et eneste sted i mit arbejde, hvor jeg har en teori om betydning, selv ikke i mere generelle diskussioner om thick description (1993, 6f). Jeg er ikke engang sikker på, hvad en teori om betydning ville være. Mit arbejde er derimod baseret på forskellige begreber - eksempelvis symbolet, reference osv. - hvilket går tilbage til den semiotiske og semantiske fagtradition. Jeg har ikke selv bidraget til diskussionen om en generel teori om mening/betydning. Selvfølgelig har jeg lært af Gottlob Frege, men jeg kaster mig ikke ud i sådan noget. Jeg lærer fra andre og prøver at bruge det.

AM: Dog skriver du, at dit syn på kultur er semiotisk og semantisk, og at kultur kan forstås som en klynge af tegn eller symboler. Desuden skriver du, at måden man kan 
afdække den indre betydning i disse symbolsystemer på, er via thick description (1993, 5, 6 og 14). Videre skriver du:

Such an approach is neither introspectionist nor behaviorist; it is semantic. It is concerned with the collectively created patterns of meaning the individual uses to give form to experience and point to action, with conceptions embodied in symbols and clusters of symbols, and with the directive force of such conceptions in public and private life (1970, 95f).

Samtidig bruger du semiologiske termer i Meaning and order in Moroccan Society (1979, 200f). Forstår du fortolkende antropologi som et semiotisk foretagende? ${ }^{4}$

CG: Nu er semiotik jo ikke kun én ting, men jeg er enig i, at jeg er interesseret i betydning og symboler - og således set kan man godt forstå mit arbejde som en semiotisk virksomhed, dog uden en generel teori om betydning. Ferdinand de Saussure og den strukturalisme, der fulgte efter ham, er ikke den tilgang, jeg bruger. Jeg har selvfølgelig lært af Saussure - ingen kan ignorere hans arbejde - men, som jeg har sagt: ligesom jeg ikke er interesseret i en selvstændig fænomenologisk videnskab, er jeg heller ikke interesseret i en selvstændig semiotisk videnskab. Den anden tradition er Charles S. Peirce som i sin fænomenologiske tilgang er lidt for meget en realist for mig - men jeg befinder mig mere i den peircianske tradition inden for semiotikken. Dog forfølger jeg ikke semiotikken som en formel, videnskabelig, abstrakt og objektiv disciplin $(1983,120)$. Så når jeg siger semiotik, mener jeg i betydningen af en generel opfattelse af tegn- eller symbolfunktionen. Men det er i den pragmatiske tradition og fænomenologiske tradition, at jeg føler mig bedst tilpas. Igen, semiotik som en quasi-logisk, quasi-formel disciplin er ikke noget for mig.

AM: Umberto Eco har, som jeg forstår det, forsøgt at skabe bro mellem de to nævnte traditioner og han - som du - placerer tegnet inden for kulturens grænser (Eco 1979, 66). Er du blevet inspireret af hans arbejde?

\footnotetext{
${ }^{4}$ Semiologien, der er formuleret af Ferdinand de Saussure, ligger inden for en lingvistisk tradition og opfattes normalt af den moderne semiotik som værende en del af semiotikkens fagtradition (Saussure 1993). Dog forholder den moderne semiotik sig ikke kun til sproget som et tegnsystem, men har bl.a. via Charles Sanders Peirce udvidet sit studieobjekt til at gælde alt, hvad der vedrører betydning og mening (Peirce 1955). For en introduktion til semiotikkens historie, se Clarke 1990. For en afklaring af tegnopfattelsen hos Saussure og Peirce, se efterfølgende note.
} 
CG: Jeg har læst noget af Ecos arbejde, men er dog ikke direkte blevet influeret af ham. Ikke fordi jeg har noget imod hans arbejde, jeg har bare ikke læst meget af ham. Han er - som jeg - lidt af en essayist. Jeg kan godt lide hans opfattelse af fortolkning, men så igen, jeg er lidt anti-strukturalistisk, hvilket betyder, at jeg holder mig væk fra hans mere formalistiske arbejde.

AM: Hvis du hævder, at du til en vis grad bruger semiotik, hvorfor kalder du så symbolet for et tegn, dvs. bruger en anden terminologi?

CG: Distinktionen, som jeg benytter mig af, kommer fra Langer (Geertz 1993, 100; Langer 1949, 60f). Jeg er faktisk ligeglad med termerne i sig selv. Jeg er villig til at bruge termen tegn, så længe det forstås, at tegnet er konceptuelt og ikke et signal (Langer 1962, 54f). Således er en mørk sky et tegn på regn, men ikke et symbol på regn undtagen i et digt (Geertz 1993, 91). Jeg har ikke noget imod termen tegn, hvis den forstås i forlængelse af Peirce og ikke Saussure. Der er forskel på et ikon, et indeks og et symbol. ${ }^{5}$

AM: Betyder det, at du fastholder, at et tegn har en reference?

CG: Ja - et tegn, forstået som et symbol, er om noget, hvilket er en bedre formulering, end at tegnet kun har en reference. Tegn har som symbol en aboutness (Langer 1962, 112 og 147ff). Så når jeg bruger termen symbol i mit arbejde, skal det forstås som et tegn, f.eks. et indeks, der bliver til et symbol via en kulturel interpretation. Hunde kan ikke - som jeg ser det - reagere på symboler. De kan kun reagere på tegn. Det berømte eksempel er fra Langer, som fortæller om en person, der træder ind i et værelse, hvor der er en hund. Personen siger ejerens navn til hunden - eksempelvis James - og hunden reagerer ved at lede efter ejeren. Hvis du gør det samme med en person, vil personen givetvis sige: "What about James”? Kan du se - der er en aboutness. Det er den distinktion, jeg ønsker at holde fast i.

AM: Hvis vi vender os mod den kritik, den fortolkende antropologi har mødt, så har eksempelvis Paul Shankman (1984) problematiseret den fortolkende antropologi som et program. Han understreger specielt problematikken med den generelle partikularisme i den fortolkende antropologi, dens opfattelse af "Cultural analysis [as] intrinsically incomplete ...” (Geertz 1993, 29) og den praktiske metode som “... guessing at meaning, assessing the guesses, and drawing explanatory conclusions from the better guesses ...” (s. 20). Videre har Talal Asad fokuseret på konstruktionen af magt og betydning fra et historisk og institutionelt perspektiv, hvilket han mener, du ikke gør (Asad 1983). Hvad er din mening om disse kritikpunkter?

CG: Jeg er selvfølgelig ikke enig i deres kritik. Hvis jeg var, ville jeg ændre det, jeg gør. Shankman har en meget overfladisk opfattelse af, hvad fortolkning er. Han taler om

\footnotetext{
${ }^{5}$ Meget kort fortalt er Peirces opfattelse af et tegn en triadisk konstruktion, udgjort af tegnets fænomenale side (repræsentamen) og dets reference (objektet). Relation imellem disse er det tredje element (interpretanten). Ved indekset er relationen kausal, ved ikonet er det kvalitativt og ved symbolet er relationen konventionelt etableret (Peirce 1955, 98f). Saussures tegn består af kun to elementer (udtryk og indhold), hvor deres relation, ifølge Saussure, er arbitrært og derfor socialt etableret (Saussure 1993, 64f).
} 
Wilhelm Dilthey, men han ved faktisk ikke, hvad der er sket inden for den tradition. Da Shankman rettede sin kritik imod mig, var Dilthey ikke oversat til engelsk, og jeg tvivler på, at han har læst ham på tysk. Derfor må jeg indrømme, at jeg ikke har ofret hans kritik megen opmærksomhed. Asad er en fremtrædende person, og her tror jeg, at der er en reel uenighed imellem os. Jeg synes selv, at jeg har brugt en konstitutionel historisk ramme i mit arbejde, hvilket han siger, jeg ikke gør. For at være helt ærlig tror jeg, at Asad er en magtreduktionist. Han er af den holdning, at det er magt, som er det afgørende og ikke tro. Hans opfattelse af, hvad en definition er, og hans efterfølgende kritik af mig, ignorerer fuldstændig det, jeg selv skrev (Asad 1993, 29). Jeg mistænker Asad for at være en marxist, som ikke mere kan være en materialreduktionist, så i stedet for er han nu en magtreduktionist.

AM: Opfatter du - i modsætning til Asad - mening som værende forud for magt?

CG: Nej - jeg tror bare ikke, at magt har en selvstændig eksistens uden for en kulturel eller historisk kontekst. Videre synes jeg, at der i øjeblikket er en tendens til, at man opfatter menneskelige fænomener som et udtryk for magtkampe. Fra dette perspektiv er betydning et skalkeskjul for en magtkamp, hvilket jeg selvfølgelig er uenig i. Men at hævde, at betydning eller mening er forud for magt, vil gøre mig til en betydningsrealist og idealist, hvilket jeg ikke er. Jeg tror bare ikke, at betydning kan reduceres til distributionen af magt.

AM: Selv om du skriver, at du ikke er til systemer ${ }^{6}(2000, x)$, så refererer du til kunst, ideologi, common sense og religion som systemer (1983; 1993). Hvordan skal det forstås?

CG: Det er et reelt spørgsmål, men jeg synes nu ikke selv, at jeg er optaget af systemer. Termen system blev kun brugt i titlen. Når man læser min analyse af kunst, religion osv., så er det, jeg afdækker, ikke så systematisk i sin natur. Jeg hævder blot, at der er en eller anden form for indre sammenhæng, som skal undersøges kontekstuelt. Det er så langt, jeg er gået med systemanalyse, og desuden bruger jeg ikke termen i mine titler mere. Dog er det Parsons' indflydelse - som selv endte med at opfatte kultur som rene systemer - der kan ses her (Parsons 1937, 762f). Jeg har dog ikke selv samme opfattelse af kultur som Parsons. Titlerne var mere et forsøg på at realisere Parsons’ program om kulturelle systemer, hvilket jeg stadig ønsker at gøre, dvs. at afdække systematiske relationer (Parsons 1951). Dog kan disse systematiske relationer kun findes i det, man studerer, og ikke før analysen via formuleringen af en generel filosofi eller generel teori. Jeg formulerer ikke generelle teorier om noget som helst!

\footnotetext{
${ }^{6}$ Dette spørgsmål lader sig desværre ikke oversætte direkte til dansk. Både i interviewet og i Available Light siger Geertz: “... I don’t do systems”, hvilket er engelsk talesprog. Betydningen er dog, at han ikke er optaget af systemer.
} 
AM: Hvad med filosofiske standpunkter forud for studiet af kultur?

CG: For det første er forud ikke det rigtige ord. Det er altid allerede. Man har altid et perspektiv, når man begynder. I mit tilfælde var det filosofi og litteratur før antropologien. Dengang var jeg interesseret i forholdet mellem samfund og praksis, hvilket stadig er min hovedinteresse. Da jeg så begyndte at læse antropologi, prøvede jeg at se samme relation i form af kultur og struktur samt praksis og senere inden for Wittgenstein-traditionen via hans handlingsbegreb. Så du har ret, man har altid et udgangspunkt. Men det er ikke en filosofisk position, som man så ændrer i konfrontationen med fakta. Man begynder med en generel tilgang til verden, og for en antropolog er det inden for en professionel kontekst. Men alligevel tror jeg, at mine grundholdninger nu er de samme som dengang, selvom jeg har udviklet mine holdninger gennem tiden.

AM: Men skal det, du producerer, når du skriver en bog, eller når du går ud i felten og analyserer, ikke have en eller anden form for selvstændig værdi eller relevans?

CG: Jo - det som er dunkelt og forvirrende er klarere, når man forstår det. Hanekampen er et godt eksempel (1993, 412f). Da jeg først begyndte at observere hanekampen, havde jeg overhovedet ikke nogen idé om, hvad der skete. Hvis man har set en hanekamp, har man set dem alle, men balineserne er lidenskabelige, når det kommer til hanekampe, og jeg kunne ikke finde ud af hvorfor. Derfor prøvede jeg at afklare det, da jeg ikke forstod det. En ren beskrivelse ville givetvis kun pege på hasardspillet, som hanekampen involverer, men det var tydeligvis mere end det. Det jeg ville, var at forstå eller afklare kampen; at forstå hvorledes deltagerne måske forstod det og samtidig prøve at vise, hvorledes en sådan analyse skulle udføres. Hanekampsanalysen er derfor en model eller et eksempel på, hvordan man udfører en sådan analyse. Man prøver at forstå det, dvs. forstå det, de forstår - prøver at forstå, hvorledes de forstår deres verden. På den måde er det fænomenologisk og hermeneutisk. Det er et forsøg på at forstå tingene fra den lokales perspektiv. Dog på vores, dvs. observatørens, præmisser.

AM: Skal man så efter analysen gå tilbage til de lokale og vise dem sine resultater?

CG: Generelt nej! Når det kommer til hanekampen, er det lidt sværere. Jeg har prøvet at gøre det, men hanekampen er baseret på en illusion, så de lokale vil ikke forstå den, som jeg gør. Hvis de gjorde, ville hanekampen eller illusionen ikke virke. Nogle gange har mennesker en naturlig modstand imod at forstå det, de gør. På den anden side gik jeg faktisk tilbage og talte med dem, om det de gjorde, men de var selvfølgelig ikke interesserede i socialvidenskab eller alternative fortolkninger af det, de gjorde. De er ikke interesseret i hanekampens hermeneutik. De ved allerede, hvad det betyder for dem. Det jeg ville var at fortælle, hvad hanekampen betyder for dem, der ikke ved det.

AM: Indeholder dit arbejde derfor også et psykologisk perspektiv?

CG: Der er vel visse psykologiske dimensioner i mit arbejde, men psykologi optager mig ikke. ${ }^{7}$

\footnotetext{
${ }^{7}$ Igen benytter Geertz sig af en almen talemåde for at understrege, at han ikke er optaget af én tilgang. I dette tilfælde formulerer han det som “... but I do not do psychology”.
} 
AM: Hvis vi skal se på din udlægning af andre menneskers opfattelse af verden fra et religiøst perspektiv, så skriver du i Islam Observed:

We look not for a universal property - 'sacredness' or 'belief in the supernatural', for example - that divides religious phenomena off from nonreligious ones with Cartesian sharpness, but for a system of concepts that can sum up a set of inexact similarities, which are yet genuine similarities, we sense to inhere in a given body of material. We are attempting to articulate a way of looking at the world, not to describe an unusual object ... The heart of this way of looking at the world, that is, of the religious perspective, is ... the conviction that the values one holds are grounded in the inherent structure of reality, that between the way one ought to live and the way things really are there is an unbreakable inner connection. What sacred symbols do for those to whom they are sacred is to formulate an image of the world's construction and a program for human conduct that are mere reflections of one another (1970, 96f).

Dette synes at ekskludere antropomorfisme, hvilket også ses i din religionsdefinition (1993, 90). Hvorfor vælger du dette perspektiv for fænomenet religion og studiet af det, og hvorledes skal vi i denne sammenhæng forstå hellige symboler, hvis vi ikke skal tale om 'det hellige'?

CG: At gøre det, dvs., at formulere en essentialistisk definition af religion er, hvad Asad anklager mig for at gøre. Ifølge Asad er det netop et kristent syn på religion, der nødvendigvis er ubrugeligt (Asad 1993). Det er selvfølgelig ikke det, jeg gør, men det er det, jeg anklages for at gøre. Jeg er mere empirisk fokuseret, og hvis man begynder med en opfattelse af det hellige i studiet af religion, så tror jeg ikke, det vil holde rent empirisk. Jeg tror ikke, at en tro på det overnaturlige nødvendigvis er en del af religion - den tidlige buddhisme ville i så fald ikke være en religion. Man kan vel lade det overnaturlige være en del af religion, men jeg er bange for, at en sådan definition og et sådant perspektiv vil være fejlagtigt. Videre tror jeg, at det overnaturlige er en vestlig idé. Selv kulturer eller samfund der tror på ånder - som f.eks. de oprindelige amerikanere gør opfatter dem ikke som værende overnaturlige, og derfor deler de ikke verden op i en naturlig og overnaturlig verden. Jeg er i det mindste åben over for, at de ikke gør det. Derfor ønsker jeg ikke at formulere en essentialistisk definition af religion.

AM: Armin Geertz foreslår i sin definition begrebet 'transempirisk' (A.W. Geertz 1999, 471).

CG: Ja, og jeg er bestemt glad for Armin Geertz' arbejde, men selv det synes at antage, at mennesker skelner mellem det empiriske og det transempiriske. Jeg tror til en vis grad at dikotomien hellig/profan, naturlig/overnaturlig eller empirisk/transempirisk er en vestlig idé, som ikke nødvendigvis altid gælder. Det er ikke min kæphest det her, jeg er bare lidt skeptisk. For det meste vil den religiøse person opfatte sin religiøse tro som værende naturlig, eller, det som vi synes, er overnaturligt som værende naturligt selvfølgelig i det omfang, at den religiøse person har begreb om det naturlige og overna- 
turlige. I relation til dette har jeg mine problemer med Melford Spiro (Spiro 1968, 91 og 96).

AM: Er det, fordi du gerne vil være så tæt på data som muligt?

CG: Jeg vil ikke sige, at jeg er tættere på data end Armin Geertz, som er en fremragende forsker. Jeg vil bare være åben og respondere over for det - bevæge mig efter data, og ikke omvendt - dvs. ikke at få data til at bevæge sig efter mig. Jeg vil ikke finde idéer, som ikke er der, såsom at skelne mellem det naturlige og det overnaturlige, medmindre det er et resultat af min analyse.

AM: Jeg kan se, at vi ikke kan undgå emnet videnskab. Armin Geertz har i sit arbejde prøvet at formulere et videnskabeligt standpunkt for studiet af religion, så vi kan hævde en videnskabelighed (A.W. Geertz 1999, 446f).

CG: Ja - det gør jeg ikke. Modellen for videnskab i antropologien er til dels taget fra naturvidenskaben, hvilket går tilbage til Edward Tylor, der normalt får folk til at søge efter love og abstrakte regulariteter, som igen går tilbage til Wissenschaft, der ikke gælder inden for Geisteswissenschaft. Jeg har dog heller ikke en skarp distinktion, når det kommer til disse to begreber. Jeg mener, at forsøget på at videnskabeliggøre socialvidenskaben, fra behaviorismen i 1920'erne til socialbiologien i dag, er destruktivt i forhold til det, jeg vil med socialvidenskaben; nemlig at hjælpe mennesker til at forstå hinanden. ${ }^{8}$ Jeg er ligeglad med, om man kalder det videnskab eller socialvidenskab, bare man ikke forstår videnskab inden for den positivistiske tradition.

AM: Men der findes jo teorier om fortolkning og derfor også faglige og teoretiske begrænsninger for fortolkning som perspektiv.

CG: Ja - jeg siger ikke, at man ikke skal tænke sig om. Jeg mener bare, at den naturvidenskabelige model ikke skal anvendes ukritisk inden for socialvidenskaberne. Jeg er ikke imod fornuft eller videnskab med et lille v.

AM: Med elimineringen af privatsproget ifølge Wittgenstein og fokuseringen på evolutionen af menneskets bevidsthed som parallel med evolutionen af kultur og opfattelsen af de kulturelle systemer som værende vejledende for menneskets perception, hvad er da din generelle holdning til den kognitive videnskab og den 'anden kognitive revolution', som den eksempelvis ses hos Mark Turner, George Lakoff, Jerome Bruner og Umberto Eco for den sags skyld? (Geertz 1963, 67; 1993, 12, 55f og 216; jf. Bruner 1983/1990; Eco 2000; Lakoff \& Johnson 1981; Lakoff \& Turner 1989; Turner 1987/1998).

CG: Det der skete med kognitionsforskningen efter den kognitive revolution var, at den fulgte den naturvidenskabelige model, dvs. A.I. (Artificial Intelligence) og

\footnotetext{
8 "Looked at in this way, the aim of anthropology is the enlargement of the universe of humane discourse" (Geertz 1993, 14).
} 
chomskyisme, som endte med at blive det, jeg kalder for en supervidenskab. Den anden kognitive revolution, som er en interessant idé, er den Bruner, i lighed med Turner og Lakoff, kalder for kulturel psykologi. Jeg synes selv, at de går i den rigtige retning, da de er imod den mere formalistiske kognitive tradition, der stammer fra Noam Chomsky. Turners og Lakoffs arbejder er interessante, men dog en smule redundant. I mit arbejde taler jeg om evolutionen af hjernen og kulturens vækst, ikke evolutionen af kulturen (Geertz 1993, 55f). Jeg tror ikke på kulturel evolution - kultur ændrer sig og vokser og måske udvikler den sig ud fra en standard. Men jeg er af den overbevisning, at kultur er involveret i vores hjernes evolution. Dog er kulturen ikke underlagt en darwinistisk udvikling.

AM: Til sidst vil jeg gerne spørge dig, hvad den fortolkende antropologis tænkelige udvikling kunne være i det nye årtusinde specielt i forhold til det postmodernistiske paradigme?

CG: Jeg tror, at postmodernismens salgsdato er udløbet. Ikke fordi postmodernismen var irrelevant - den har haft utrolig kritisk vigtighed. Men den kommer nok ikke videre som en selvstændig tradition. Jeg synes, at vi bør lytte og lære af postmodernisterne og derefter bevæge os videre. De har med deres kritik hjulpet til med at afklare fundamentale begreber såsom kultur og fortolkning, men de vil ikke kunne fortsætte som et selvstændigt program. Men deres kritik og efterfølgende afklaring har ændret retningen af antropologien. Derfor vil min form for fortolkende antropologi være meget påvirket af postmodernismen. Vi kan for eksempel ikke mere have en simpel opfattelse af, hvad fortolkning er, og vi er nu i højere grad bevidste om problemerne med meningsrealisme osv. Alt dette er utroligt vigtigt. Personligt har de bestemt influeret mig, og jeg hører til dels stadig til blandt postmodernisterne. Hvad angår kulturel antropologi vil den fortsætte i rimelig kontinuitet med sin fortid.

AM: Tror du at fortolkende antropologi vil blive mere systematisk gennem tiden?

CG: Jeg tror, at discipliner har det med at bevæge sig i bølger, hvor de bliver mere systematiske, indtil de bliver kvælende, hvorefter man bevæger sig i forskellige retninger og derfor fragmenterer. Jeg tror ikke, at en simpel lineær bevægelse imod en systematisering er i vente for fortolkende antropologi, selvom jeg kunne forstille mig, at dele af den vil blive mere systematisk og blive taget for givet. Der er næsten en dialektik mellem systematisering og fornyelse. Men - jeg kan ikke forudsige fremtiden! 


\section{Litteratur}

ASAD, TALAL

1983 “Anthropological Conceptions of Religion: Reflections on Geertz”, Man, New Series, Vol. 18, No. 2, 237-259.

1993 Genealogies of Religion. Discipline and Reasons of Power in Christianity and Islam, Baltimore.

BERGER, PETER \& THOMAS LUCKMANN

1967 The Social Construction of Reality, London.

BRUNER, JEROME

1983 In Search of Mind, New York.

1990 Acts of Meaning, Cambridge.

Clarke, DAVID S. JR.

1990 Sources of Semiotics - Readings with Commentary from Antiquity to the Present, Southern Illinois.

ECO, UMBERTO

1979 A Theory of Semiotics, Bloomington [1976].

2000 Kant and the Platypus - Essays on Language and Cognition, London.

GEERTZ, ARMIN W.

1999 "Definition as Analytical Strategy in the Study of Religion”, Historical Reflections, Vol. 25, No. 3, 445-475.

GEERTZ, CLIFFORD

1960 The Religion of Java, Glencoe.

1963 Peddlers and Princes - Social Development and Economic Changes in Two Indonesian Towns, Chicago and London.

1966 "Person, Time, and Conduct in Bali - An Essay in Cultural analysis", Cultural Report, Series No. 14, Southeast Asia studies, Yale University.

1970 Islam Observed - Religious Development in Morocco and Indonesia, Chicago and London [1968].

1980 Negara - The Theatre State in Nineteenth Century Bali, Princeton.

1983 Local Knowledge - Further Essays in Interpretive Anthropology, New York.

1993 The Interpretation of Cultures, London [1973].

1995 After the Fact - Two Countries, Four Decades, One Anthropologist, Cambridge and London.

2000 Available Light - Anthropological Reflections on Philosophical Topics, Princeton.

GEERTZ, ClifFORD AND HILDRED \& ROSE LAWRENCE

1979 Meaning and Order in Moroccan Society - Three Essays in Cultural Analysis, Cambridge.

HANDLER, RICHARD

1991 “An Interview with Clifford Geertz”, Current Anthropology, Vol. 32, Issue 5, 603-613.

Kroeber, A.L. \& Clyde KLUCKHOHN

1963 Culture - A Critical Review of Concepts and Definitions, New York [1952].

LAKOFF, GEORGE \& MARK JOHNSON

1981 Metaphors We Live By, Chicago and London.

LAKOFF, GEORGE \& MARK TURNER

1989 More than Cool Reason, Chicago.

LANGER, SUSANNE K.

1949 Philosophy in a New Key, New York [1948].

1962 Philosophical Sketches, Baltimore.

PARSONS, TALCOTT

1937 The Structure of Social Action, New York. 
1951 The Social System, Glencoe.

PEIRCE, CHARLES SANDERS

1955 Philosophical Writings of Peirce, Justus Buchler, ed., New York.

RICOEUR, PAUL

1970 Freud and Philosophy - An Essay on Interpretation, oversat af Denis Savage, New Haven and London.

RYLE, GILBERT

1976 The Concept of Mind, New York [1949].

SAUSSURE, FERDINAND DE

1993 Course in General Linguistics, oversat af Roy Harris, London.

SHANKMAN, PAUL

1984 "The Thick and the Thin: On the Interpretive Theoretical Program of Clifford Geertz", Current Anthropology, Vol. 25, No. 3, 261-280.

SPIRO, MELFORD E.

1968 "Religion: Problems of Definition and Explanation", Anthropological Approaches to the Study of Religion, Michael Banton, ed., London [1966, 85-126].

TURNER, MARK

1987 Death is the Mother of Beauty, Chicago.

1998 The Literary Mind, Oxford and New York.

\section{Summary}

I had the honour of interviewing Professor Clifford Geertz at the Institute for Advanced Studies, Princeton, USA on 18 October 2000. The interview focused on Geertz' theoretical conceptions, the tradition which he draws on, the critique he has encountered, and interpretive anthropology's future development. Of particular interest was the clarification of his much debated method, his definition of symbol and his famous definition of religion as a cultural system. Geertz emphasizes that he attempts to exercise an applied pragmatic phenomenological and hermeneutical method without any general theory (or philosophy) of meaning, phenomenology, or culture. He maintains that he only has a conceptual framework inspired by different scholars, who nevertheless have a similar focus and perspective, i.e., meaning and symbol. In relationship to this, Geertz defines his symbol within the Peircian semiotic tradition. Therefore, the term symbol is understood as a sign (an index for example), which becomes a symbol via a cultural interpretation. Furthermore, his definition of religion as a cultural system is, in his view, a non-essentialistic definition and therefore not - as Talal Asad claims - ethnocentric. Although it is Geertz' opinion that interpretiveanthropology has been influenced by postmodernism, he predicts that interpretive anthropology's future development will be in reasonable continuity with its past.

Arun Micheelsen

Stud.mag.

Universitetsparken, kol. 3, 3., v. 143

Aarhus Universitet

8000 Århus C 